\title{
Early correctional and pedagogical assistance to children with autism as a means of improving their quality of life
}

\author{
Elena Timofeeva ${ }^{1 *}$, Ksenia Timofeeva $^{1}$, and Vladimir Shinkarenko $^{2}$ \\ ${ }^{1}$ Moscow City University, Institute of Special Education and Psychology, Moscow, Russia \\ ${ }^{2}$ Belarusian State Pedagogical University named after Maxim Tank, Institute of Inclusive Education, \\ Minsk, Belarus
}

\begin{abstract}
The present article deals with the organization and implementation of correctional care for younger children with autism spectrum disorders. The authors reveal key aspects of the problems underlying the speech and nonspeech difficulties of this category of children, as well as consider the topic of the only generally accepted method (applied behavior analysis) that is widely used when working with these children, and prove the expediency of a different approach to the complex correction of speech problems in children with communication disorders. The approach is based on the identified peculiarities of the speech and nonspeech problems of children with autism. The authors justify the choice of contemporary foreign methods (Tomatis, Floortime, and Sensory Integration) in the correction of speech and behavior of children with communication disorders based on the results of the conducted ascertaining experiment. Based on a comparative analysis of the results of ascertaining and forming experiments in the control and experimental groups, it has been proved experimentally that establishing an emotional and communicative component of the mental development of the child, as well as improving the processing of auditory, tactile, vestibular, and proprioceptive sensation speed up the corrective process that plays a crucial role in speech development and the development of nonlanguage functions. The significance of this study concerns the evidence-based use of a comprehensive approach to the correction of children with autism in the sensitive period of their development (from two to four years). Early comprehensive care provides a chance to achieve success in the social and speech development of these children by the beginning of school education (from seven to eight years), which will significantly improve the quality of their lives and contribute to the best integration into society.
\end{abstract}

Keywords: autism spectrum disorders, sound therapy, Tomatis method, sensory integration, Floortime, speech therapy.

* Corresponding author: timofeevaea402@mail.ru 


\section{Introduction}

Certainly, education should not be divorced from the needs of the man of today, his life in the city. The urgent goal of modern education should be to improve the quality of life of people. One of the topical issues of correctional pedagogy is the integration of people with special needs into contemporary society. An important topic of discussion in this field is children with autism spectrum disorders, their education, and integration into society. It is obvious that the Russian mentality and domestic defectology do not fully meet the needs of this category of children.

It should be noted that throughout the world, the main scientific method of helping children with autism is considered to be the method of applied behavior analysis. In Russian defectology, the emotional and semantic approach developed by a group of scientists (O.S. Nikolskaya, E.R. Bayenskaya, M.M. Libling) is used in correctional work [1]. Respecting both correctional methodologies, the authors believe that neither of them takes into account all the social and educational needs of children with autism spectrum disorders, which reduces the possibility of integrating this category of children into society and worsens the quality of their social life.

Understanding that the main function of speech is the ability of a person to communicate, the authors argue that speech dysontogenesis is the central pathological link of this disorder. However, the strategies of correctional speech work remain insufficiently studied by the national defectology. In Russia, there are no generally recognized, scientifically proven methods of speech therapy with this category of children. At that, the method of applied behavior analysis, which employs speech techniques, does not consider the emotional aspect and sensory problems of a child with autism as part of its approach.

Based on the above, the authors attempted to find new effective methods of correction that could comprehensively address the problems of children with autism, which, in turn, would improve their quality of life, and broaden the opportunities for their integration into society.

The novelty of the study is due to the proposed new approach to the complex correction of speech problems in children with autism. This approach is based on the identified development peculiarities of this category of children.

The research hypothesis is formulated as follows: a comprehensive approach to solving speech and nonspeech problems in children with autism significantly reduces the total time of corrective action, which allows children to reach the lower limit of speech and social and communicative norms by the beginning of school education.

The research goal consists in substantiating the need for a comprehensive approach to early correctional and pedagogical assistance to children with communication disorders.

Research objectives are as follows:

- To identify the speech and nonspeech features in children with autism spectrum disorders.

- To identify key strategies for an integrated approach to identified problems in children's development.

- To establish the relationship between an integrated approach and the success of correctional work in children with communication disorders.

\section{Methods and materials}

Research methods included theoretical, empirical, analytical, and statistical techniques.

The study involved 256 children aged from one year and 10 months to four years and two months with no speech skills or with its rudiments. Among them, $14 \%$ of children were with impaired communication development (36 people, of which 32 were boys and four 
were girls). The state of their speech system was studied, as well as other development features (game activity, nonverbal communication, cognitive and motor sphere, and features of sensory information processing).

As a result of the study, the following features of the speech system were revealed in these children with communication disorders:

1. The impaired communicative function of speech (lack or limited ability to maintain a dialogue, difficulties with the use of the words yes and no).

2. The impaired impressive speech: difficulties in speech comprehension. In all 36 children, violations of the semantic nature were manifested as clearly as the violation of the communicative aspect of speech.

3. Speech stereotypies (echolalia and perseverations). Echolalia was not detected in only eight children out of 36 , while the remaining 28 children used this unusual speech method to varying degrees.

4. Features of the prosodic aspect of speech (unusual intonation, stuttering, tachylalia, chanting of speech). Only 10 children out of 36 did not have features in the prosodic system of the language.

5. Hyperlexia. Increased interest in letters and numbers (under the age of three years) was experienced by 10 children in the study group: children noticed letters/numbers everywhere, fixed eyes on their image for a long time, examining and pronouncing them

6. Difficulties with the use of personal pronouns. Almost all children experienced significant difficulties in using personal pronouns, namely, did not use them at all, used them in the second person and/or in the form of echolalia.

Other features in the development of children with communication disorders included:

1. Features of the nonverbal communication development methods. The following features were observed: lack or restriction of eye contact, poor and/or unnatural facial expressions, lack of pointing gesture, and joint attention.

2. Features of the game activity. All children in the study group had a limited and/or looped play interest. Many children were distinguished by unusual interests.

3. Motor stereotypies/stimming. Stereotypical movements were observed in almost $80 \%$ of children ( 28 children). These were bouncing, walking on tiptoes, pumping hands/wrists, spinning, swinging, etc. Four children used oral stereotypical movements: children bit their own hands. Studying the sensory integration theory of J. Ayres, it was suggested that motor stereotypies might have resulted from impaired processing of sensory information (vestibular, or proprioceptive) [2].

4. Fears or a complete lack of a sense of security. Almost $40 \%$ of children (14 children) had various fears (associated with height, unstable surface, physical restriction, and confined space). At that, 35\% (12 children) completely lacked a sense of security (children ran out on the road, climbed to a dangerous height, felt pain badly). Based on the sensory integration theory of Ayres, it was assumed that these behavioral features could be attributed to the difficulties of integrating sensory stimuli, primarily vestibular and proprioceptive.

5. Selective eating behavior/oral examination of subjects. Thus, 16 children out of 36 had a selective attitude to food. These children, even at an early stage of their development (from nine months to 1.5 years) practically did not explore the environment with their mouths. Other 12 children, on the contrary, after 2-2.5 years continued to be in constant oral search: pulled in the mouth inedible things, and licked the objects surrounding them. These features of orality led to the idea of a violation of the processing of tactile information (according to sensory integration theory of Ayres).

6. Lack of or limited ability to imitate. This feature applied to both game activities and impressive speech. Some children (22) preferred to look at an adult as if casually (with lateral vision), fixing attention on some of their visual sensations (spinning wheels, light 
glare, letters, and numbers, etc.). Often the mimic emotional response (smile) appeared from these visual stimuli rather than from the person's face. This specificity of the visual system was attributed also to the peculiarities of processing sensory information (according to the Ayres's theory).

7. Lack of self-service and/or toilet skills. Poor day and/or night sleep.

These problems were observed in most of the children.

Based on the identified features in the children's development, all children (36) were divided into two identical groups of 18 people (16 boys and 2 girls). Each group included children with approximately the same level of speech development, communication capabilities, age (from two to four years), and sex.

Next, the authors have built strategies for correctional speech therapy work in such a way that each aspect of it concerned certain features of children's development. All the development features were conditionally divided into three groups of problems:

- problems associated with impaired processing of auditory information;

- behavioral problems associated with impaired processing of tactile, vestibular, and proprioceptive information;

- problems related to communication disruption;

Thus, the authors have compiled a correction Protocol that included a set of measures aimed at improving the processing of various sensory information as well as improving emotional and communicative behavior in general, and the speech system, in particular.

The Protocol included the following corrective measures:

1.Improving the processing of auditory information: working on the listening skill according to the method of $\mathrm{A}$. Tomatis.

The Tomatis method of neurosensory stimulation was created by the French ENT doctor and phoniatrist Alfred Tomatis in the 60s of the last century. The method represents a system of training listening. A French scientist, producing specific processing of music and voice, has proved that brain stimulation by means of the auditory system not only changes the quality of listening but also improves the motor, emotional, and cognitive abilities of a person. Tomatis has explained these improvements by saying that the ear plays a crucial role in information processing and is seen as a single sensorimotor organ that opens up access to the entire nervous system. The success of the Tomatis method has been proven by numerous studies in various countries [3-5]. Ayres also emphasized that good integration of auditory sensations contributed to speech development.

2.Improving the processing of other sensory information (tactile, vestibular, and proprioceptive).

The Ayres Sensory Integration (SI) theory is aimed at the neurophysiological justification of the connection of sensory information processing with the child's behavior and learning. Ayres explains the process of sensory integration as the brain's ordering of sensory sensations that come from the environment every second. If the sensations come in an organized (integrated) way, the brain can perceive them adequately and use them for further learning. Under the term "sensory sensations", the author understands auditory, vestibular, proprioceptive, tactile, and visual sensations. Based on the sensory integration theory, the authors of the present work developed a set of classes aimed at improving sensory integration (vestibular, proprioceptive, and tactile sensations).

3. Improving the emotional and communicative side of mental development

The fundamental method for solving this problem is the Floortime method, which was developed by S.I. Greenspan. The purpose of this method is to involve the child in the system of emotional relationships with other people, taking into account his individual characteristics. Strategies of the method are joining the unusual interests of the child, sharing his interest and pleasure with him, giving meaning to joint actions $[6,7]$. 
Studying the world's correctional methods, the authors found an interesting experience of foreign colleagues who used the method of "Intensive interaction" when working with autism [8]. This method involves using the patient's body language to attract their attention and emotionally involve them in the communication process. It seems that this method is very close to the authors' understanding of the complex correction process of children with autism.

The integrated correction process in both groups lasted two years. The authors conducted classes with the experimental group (EG) using the above Protocol, while in the control group (CG), classical speech therapy classes aimed at improving speech functions were conducted. Based on the results of the formative experiment, the dynamics of speech development in each group were tracked using a point system. The state of impressive and expressive speech was assessed based on speech ontogenesis.

Assessment of impressive speech:

1 point - lack of understanding of speech/understanding of intonation aspects of speech;

2 points - understanding words supported by gesture and/or a familiar situation;

3 points - understanding words not supported by gesture and/or a familiar situation;

4 points - understanding a short phrase;

5 points - understanding phrasal speech, while experiencing difficulties in understanding some vocabulary and complex grammatical forms.

Assessment of expressive speech:

1 point - complete absence of active speech, sound complexes;

2 points - the initial babbling, the late canonical babbling;

3 points - words, including echolalia;

4 points - the rudiments of phrasal speech, the beginning of dialogic speech;

5 points - a detailed phrasal speech with a lack of lexical and grammatical design.

The state of nonspeech functions of children in both groups after the formative experiment was evaluated as well based on observation and parents' assessments:

1 point - no changes;

2 points - improved slightly;

3 points - improved significantly;

4 points - some nonspeech problems had completely disappeared.

\section{Results and discussion}

Using the Tomatis listening training system, the authors noted that all children in the EG had shown more significant improvements in speech development than in the children of CG. Improvements related to both impressive and expressive speech, its nominative and predictive functions, namely:

- understanding of speech had improved (verbal instructions not supported by the gesture, prepositional constructions);

- speech activity had increased (late canonical babble, words, and phrasal speech);

- opportunities for using dialogic speech had increased;

- prosodic components of speech had improved.

Assessing the results of the formative experiment in points, it was revealed that in the $\mathrm{EG}$, the total number of points increased almost 2.5 times (by 39 points), while in the CG, the total increase in points was only 17 points (increased 1.7 times). These results reflected expressive speech. In the impressive speech, the most successful dynamics were observed in EG (an increase by 30 points) while in CG the increase amounted to only 10 points.

Besides, all children in the EG compared to those in the CG experienced the most significant changes which related to nonspeech components of their development (socioemotional, sensory and neurological statuses: behavior, mood, sleep, motor skills and 
dexterity, self-service, and toilet skills improved; motor stereotypes and fears decreased or completely disappeared).

\section{Conclusion}

Thus, the authors have concluded that the improvement of sensory sensations to a greater extent accelerates the correction process in children with impaired communicative development. Complementing the classical speech therapy techniques with the methods of Tomatis, Sensory Integration, and Floortime used in the sensitive period of child's development (from two to four years), the total time of corrective action can not only be reduced but also one can count on the fact that these children will be able to achieve success in their social and speech development by the beginning of school education. This circumstance will significantly improve the quality of life of children with autism spectrum disorders and will contribute to their best integration into society.

One should take into account the fact that Russian defectology is very slow in studying the methods mentioned in this article. This conclusion is proved by the fact that there is just one fundamental Russian scientific work devoted to sensory integration [9]. In this work, Yu.E. Sadovskaya emphasizes that manifestations of sensory integration disorders can occur in different nosological groups of children with health limitations, including children with autism. It should be noted that the global experience of using the sensory integration method in the correction of children with autism is quite broad [10-14].

In Russia, there are practically no studies concerning the Tomatis neurosensory technique for improving listening skills in preschool children [15], while in global practice, this method is successfully used, including working with children with autism [3-5]. These circumstances impose significant restrictions on the popularization of these methods in Russia. In this regard, the authors believe that the use of the above methods with a larger sample of younger children with communication and speech difficulties can be a prospect for further research.

\section{References}

1. O.S. Nikolskaya, E.R. Bayenskaya, M.M. Libling, Autichnyy rebenok. Puti pomoshchi [Autistic child. Ways to help] (Terevinf, Moscow, 2020)

2. A.J. Ayres, Sensory Integration and the Child Understanding Hidden Sensory Challenges (Western Psychological Services, Los Angeles, CA, 1979)

3. B.A. Corbett, K. Shickman, Journal of Autism and Developmental Disabilities, 38(3), 562-566 (2008). https://doi.org/10.1007/s10803-007-0413-1

4. T. Gilmor, International Journal of Listening, 13(1), 12-23 (2012). https://doi.org/10.1080/10904018.1999.10499024

5. J. Gerritsen, Journal of Autism and Developmental Disorders, 38(3), 567 (2008). https://doi.org/10.1007/s10803-007-0471-4

6. S. Greenspan, S. Wieder, Na ty s autizmom: ispol'zovaniye metodiki Floortime dlya razvitiya otnosheniy, obshcheniya i myshleniya [Engaging Autism: Using the Floortime Approach to Help Children Relate, Communicate, and Think] (Terevinf, Moscow, 2018)

7. S. Wieder, S.I. Greenspan, Autism: international scientific and practical journal, 7(4), 425-435 (2003). https://doi.org/10.1177/1362361303007004008 
8. J. Horwood, Ph. Caldwell, Using Intensive Interaction and Sensory Integration: A Handbook for Those who Support People with Severe Autistic Spectrum Disorder (Jessica Kingsley Publishers, London, 2008)

9. Yu.Ye. Sadovskaya, Narusheniye sensornoy obrabotki i dispraksii u detey doshkol'nogo vozrasta [Sensory processing impairment and dyspraxia in preschool children], Thesis (Dmitry Rogachev National Research Center of Pediatric Hematology, Oncology and Immunology, Moscow, 2011)

10. B.A. Pfeiffer, K. Koenig, M. Kinnealey, M. Sheppard, L. Henderson, American Journal of Occupational Therapy, 65(1), 76-85 (2011). https://doi.org/10.5014/ajot.2011.09205

11. G.T. Baranek, Journal of Autism and Developmental Disorders, 35(2), 397-422 (2002). https://doi.org/10.1023/A:1020541906063

12. P. Aquilla, E. Yack, Sh. Sutton, Building bridges through sensory integration; Therapy for children with autism and other pervasive developmental disorders (Sensory World, Arlington, 2015)

13. U. Kiesling, Sensornaya integratsiya v dialoge: ponyat' rebenka, raspoznat' problemu, pomoch' nayti balans [Sensory integration in the dialogue: to understand the child, recognize the problem, help to find a balance] (Terevinf, Moscow, 2017)

14. T. Delaney, Razvitiye navykov u detey s autizmom: effektivnaya metodika igrovykh zanyatiy s osobymi det'mi [Developing Basic Skills in Children with Autism: An Effective Method of Play Activities for Special Children] (Rama Publishing, Ekaterinburg, 2016)

15. V.L. Yefimova, I.A. Lysova, Comprehensive Child Studies, 1(2), 98-106 (2019). https://doi.org/10.33910/2687-0223-2019-1-2-98-106 